\title{
Tasa de interés de referencia, agregados monetarios y ciclos económicos ${ }^{1}$
}

\section{Reference interest rate, monetary aggregates and economic cycles}

\author{
Pablo Hermenegildo Rivas Santos ${ }^{2}$
}

\section{RESUMEN}

El presente Aatículo analiza cualitativamente y cuantitativamente los efectos del control de la tasa de interés de referencia y de los agregados monetarios (por parte del Banco Central de Reserva) sobre la estructura productiva y los procesos de coordinación e interacción económica de la sociedad. Se verifica cuantitativamente que la relación baja tasa de interés de referencia-alto nivel de los agregados monetarios y Comportamiento Cíclico del Producto Bruto Interno define las fases de recuperación y auge de los sectores productivos más intensivo en tiempo y capital; y las fases de ralentización y recesión de esos sectores productivos.

Palabras claves: Tasa de interés; agregados monetarios; auge; reversión.

\section{ABSTRACT}

This article qualitatively and quantitatively analyzes the effects of the control of the reference interest rate and of the monetary aggregates (by the Central Reserve Bank) on the productive structure and the processes of coordination and economic interaction of society. It is verified quantitatively that the relation low interest rate of reference-high level of monetary aggregates and Cyclical Behavior of the Gross Domestic Product defines the phases of recovery and boom of the productive sectors more intensive in time and capital; and the phases of slowdown and recession

\footnotetext{
${ }^{1}$ La motivación que originó la presentación del presente artículo es dar una explicación monetaria de los ciclos económicos que ocurren en las economías nacionales, por lo que el artículo es de carácter teórico. ${ }^{2}$ Profesor de Economía e investigador del Instituto de Investigaciones Económicas de la Facultad de Ciencias Económicas de la Universidad Nacional Mayor de San Marcos. Correo Electrónico: privass@unmsm.edu.pe

(C) Los autores. Este artículo es publicado por Pensamiento Crítico de la Facultad de Ciencias Económicas, Universidad Nacional Mayor de San Marcos. Este es un artículo de acceso abierto, distribuido bajo los términos de la licencia Creative Commons Atribucion - No Comercia_Compartir Igual 4.0 Internacional. (http:// creativecommons.org/licenses/by-nc-sa/4.0/) que permite el uso no comercial, distribución y reproducción en cualquier medio, siempre que la obra original sea debidamente citada.
} 
of these productive sectors.

Keywords: Interest rate; monetary aggregates; boom; reversal.

Clasificación JEL: E. Macroeconomics and Monetary Economics, E 52 Monetary Policy.

\section{Introducción}

Cuando el Banco Central de Reserva del Perú BCRP mantiene baja la tasa de interés de referencia y aumenta los agregados monetarios como la liquidez ( según los Glosarios de términos económicos del BCRP) genera auge y optimismo que, forzosamente, tarde o temprano se revierten en una recesión.

El auge que sigue a la política de los bancos de prestar a una tasa de interés inferior a la tasa de interés de mercado, sube los precios de los factores de producción (mientras los precios de los bienes de consumo suben en un grado más moderado) reforzando la tendencia a reducir la tasa de interés de los préstamos; según Von Hayek (1978). Pero pronto aparece un movimiento opuesto; pues esa subida de los precios de los factores de producción y de los bienes de consumo eleva esa tasa de interés de los préstamos, aproximándose hacia la tasa de interés de mercado. Ese auge causado por esa Política Monetaria Expansiva en última instancia se revierte en una recesión.

Esa perturbación de la tasa de interés de mercado genera procesos de interacción social que (movidos por la capacidad coordinadora de la función empresarial que busca aprovechar oportunidades y evitar pérdidas) revierte esa descoordinación y esos errores cometidos. Así, analizaremos las causas por las que se revierte esa descoordinación intertemporal causado por tal Política Monetaria Expansiva, según Neira, Bagus y Rallo (2010).

\section{Tasa de interés de referencia en niveles bajos, agregados monetarios en niveles altos y estructura productiva}

La política monetaria expansiva materializada en forma de aumentos de la oferta de créditos afecta la estructura productiva ya que la creación de créditos al aumentar la oferta de crédito en un primer momento ensancha y alarga las etapas de la estructura productiva. 
Para ensanchar y alargar las etapas de la estructura productiva se conceden créditos a los procesos productivos que constituyen cada una de las etapas productivas: en el caso del crédito concedido para financiar la producción de bienes de consumo duradero, su efecto es ensanchar y alargar la estructura productiva, ya que los bienes de consumo duradero son económicamente similares a los bienes de capital a lo largo de todo el periodo de tiempo durante el cual puedan seguir prestando sus servicios. Así, esa mayor concesión de créditos aumentará la cantidad y calidad de esos bienes de consumo duradero.

El alargamiento de la estructura productiva se origina porque tal política monetaria expansiva introduce nuevo dinero en el sistema económico que (al concederse en forma de créditos) reduce temporal y artificialmente la tasa de interés del mercado de crédito y facilita las condiciones económicas y contractuales que exigen a sus clientes a la hora de concederles créditos.

Esta reducción artificial de la tasa de interés aumenta el valor presente de las inversiones de largo plazo, ya que sube la corriente esperada de rendimientos de esas inversiones al descontarse a esa tasa de interés reducida; y hace que parezcan rentables inversiones que hasta ese momento no lo eran, dando lugar a que aparezcan nuevas etapas más alejadas del consumo más intensivas en bienes de capital. Así, el alargamiento y ensanchamiento de las etapas productivas se produce, como efecto de las mayores facilidades crediticias que la banca concede a esa tasa de interés reducida artificialmente, tal como manifiesta Von Mises (1980).

Los empresarios al iniciar esas inversiones de largo plazo ensanchando y alargando las etapas de la estructura productiva actúan como si el ahorro hubiese aumentado. Esto significa que los empresarios al responder a esa concesión de créditos a tasas de interés reducidas artificialmente actúan como si el ahorro hubiera aumentado; impulsando una descoordinación del comportamiento de los agentes económicos.

Los empresarios al invertir; alargan lateral y longitudinalmente la estructura productiva sin que los consumidores hayan decidido aumentar su ahorro en el volumen necesario para financiar esas nuevas inversiones. Así, el control de la tasa de interés de referencia 
en niveles bajos y los agregados monetarios en niveles altos induce a los empresarios a error de cálculo económico sobre cuál debe ser el resultado de sus inversiones. Este error masivo se origina porque la tasa de interés del mercado de créditos es reducida temporalmente por los bancos en el proceso de expansión del crédito. Von Mises (1980) cita que el ejercicio sistemático de la coacción y la manipulación de los indicadores del mercado, resultado de la intervención gubernamental o de la concesión de privilegios por parte del gobierno a grupos de interés (sindicatos, bancos) impiden crear y descubrir la información necesaria para coordinar la sociedad, generándose de manera sistemática graves desajustes y descoordinaciones sociales.

Esa reducción artificial de la tasa de interés falsea el cálculo empresarial, porque pese a que no hay una mayor cantidad de bienes de capital disponibles, se incluye en tal cálculo parámetros que sólo proceden en el supuesto de haber aumentado la cantidad de bienes de capital. Consecuentemente, el resultado induce a error. Ese cálculo hace que parezcan rentables inversiones que no lo serían; si la tasa de interés no se hubiera reducido artificialmente mediante esa política monetaria expansiva. En ese escenario con alta oferta del crédito y baja tasa de interés, los empresarios se embarcan en la realización de tales inversiones. Comienza el periodo de auge. Como todo ahorro se materializa en bienes de capital, aunque en el inicio; estos bienes de capital sean los bienes de consumo que quedan sin vender al aumentar el ahorro.

La descoordinación se manifiesta en el surgimiento de un periodo de optimismo exagerado que se basa en que los agentes económicos se sienten capaces de alargar la estructura productiva sin verse forzados paralelamente a sacrificarse reduciendo su consumo para generar ahorro. En ese período, los empresarios ensanchan y alargan las etapas de los procesos productivos sin que tal previo ahorro se haya realizado.

Esta descoordinación no puede ser más patente; ni el exceso inicial de optimismo más justificado, pues parece como si fuera posible emprender procesos de producción más largos sin ningún sacrificio ni acumulación previa de capital. Va generándose un error masivo de los empresarios que inician inversiones que consideran rentables, cuando no lo son; porque la reducida tasa de interés de referencia al falsear el cálculo económico, eleva 
el valor presente de esas inversiones. Este error alimenta un optimismo generalizado, basado en la creencia de que es posible ensanchar y alargar las etapas de los procesos productivos sin que nadie se haya visto forzado a ahorrar. La descoordinación intertemporal se agranda cada vez más: los empresarios invierten como si el ahorro de la sociedad no dejara de crecer; los consumidores consumen a un ritmo inalterado y no se preocupan por aumentar su ahorro.

Se debe considerar las características del proceso de auge: $1^{\circ}$ la tasa de interés se reduce en términos relativos; $2^{\circ}$ las tasas de interés a corto plazo caen; $3^{\circ}$ las tasas de interés a largo plazo también caen; $4^{\circ}$ la cotización de las obligaciones se eleva; $5^{\circ}$ se incrementa la velocidad de circulación del dinero; $6^{\circ}$ suben las acciones en la bolsa; $7^{\circ}$ el valor de los inmuebles comienza a crecer aceleradamente; $8^{\circ}$ se produce un auge industrial y surge una gran cantidad de emisiones de títulos en el mercado primario; $9^{\circ}$ el precio de los recursos naturales y los bienes intermedios crece; y, $10^{\circ}$ el mercado de valores experimenta un crecimiento desorbitado que se basa en la expectativa de un aumento ininterrumpido de las ganancias empresariales.

\section{Reacción del mercado ante la Política Monetaria Expansiva}

Para explicar las razones que revierten ese auge, retrotraemos los fenómenos macroeconómicos (auge, recesión y desempleo) a sus causas microeconómicas. Así, los 6 efectos microeconómicos que explican esa reversión del auge de acuerdo a Lucas (1987):

\section{La subida del precio de los factores de producción}

Esta subida se debe al efecto combinado de 2 causas microeconómicas que se refuerzan mutuamente:

a) la mayor demanda de factores de producción de los empresarios de las etapas más alejadas del consumo (gracias a los nuevos créditos que les concede el sistema bancario) y

b) la menor oferta de factores de producción ya que no se liberan factores de producción de las etapas más cercanas al consumo para que se ofrezcan a esas etapas más alejadas del consumo (al 
haberse producido tal política monetaria expansiva sin respaldo de un aumento previo del ahorro).

Esta subida progresiva del precio de los factores de producción se acelera por la competencia entre empresarios de las diferentes etapas del proceso productivo que, con el deseo de atraer factores de producción hacia sus proyectos, están dispuestos a pagar mayores precios por dichos factores; precios que pueden pagar gracias a la nueva liquidez que reciben de la banca en forma de créditos sin respaldo de un aumento previo del ahorro de la sociedad, de acuerdo a la opinión de Mundell (1971). Esta subida de precio de los factores de producción eleva el costo de las nuevas inversiones que se inician respecto de lo inicialmente presupuestado. Pero, este efecto, por sí solo, aún no es suficiente para acabar con la ola de optimismo; y los empresarios, que todavía se sienten seguros y respaldados por la banca, siguen adelante con sus inversiones.

\section{2o La subida del precio de los bienes de consumo.}

Después de un periodo de tiempo más o menos largo, el precio de los bienes de consumo sube más deprisa mientras que el precio de los factores de producción no sube tan deprisa. Esta subida se debe al efecto combinado de 3 causas microeconómicas que se refuerzan mutuamente, expresa Mundell (1971).

a) El aumento del ingreso de los factores de producción aumenta la demanda de bienes de consumo sí permanece constante la tasa de preferencia temporal de los agentes económicos y, por tanto, permanece constante la parte de sus ingresos que dedican al ahorro.

b) El alargamiento de los procesos productivos; y la mayor demanda de factores de producción de las etapas más alejadas del consumo (en el corto y mediano plazo) ralentiza la producción de bienes de consumo. Esta reducción en el ritmo de la llegada de bienes de consumo al mercado se explica: por el retiro de factores de producción de las etapas más cercanas al consumo, con lo cual estas etapas experimentan una escasez de factores de producción que reduce la producción y la 
entrega inmediata de bienes de consumo al mercado; y por la incorporación (a esos alargados procesos productivos) de un mayor número de etapas más alejadas del consumo que reduce (a corto plazo) el ritmo de producción de bienes de consumo (que durará todo el periodo de tiempo que sea necesario hasta completar y culminar esos nuevos procesos de inversión recién emprendidos). Esos alargados procesos productivos; conforme más largos sean (conforme más etapas incorporen) se hacen más productivos; pero mientras esos nuevos procesos de inversión no se culminen, no permitirán la llegada de un mayor número de bienes de consumo al mercado.

Así, el efecto de ese aumento del ingreso de los factores de producción y, por tanto, de ese aumento de la demanda de bienes de consumo combinado con el efecto de la ralentización o la disminución a corto plazo de la llegada de bienes de consumo al mercado, explica que el precio de los bienes de consumo sube más deprisa que ese aumento del ingreso de los factores de producción.

c) El efecto del aumento de la demanda de bienes de consumo causada por la aparición de ganancias empresariales artificiales como resultado de tal política monetaria expansiva. La creación de créditos supone, un aumento de la oferta monetaria y un aumento del precio de los bienes de consumo y de los factores de producción que distorsiona el cálculo empresarial. Los empresarios calculan sus costos en función de su costo histórico y de la capacidad adquisitiva que tenía el dinero cuando el proceso inflacionario aún no se había iniciado; y calculan sus ingresos sobre la base de unos ingresos cuyas unidades monetarias tienen una capacidad adquisitiva más reducida. Todo esto lleva a que surjan ganancias artificiales; lo que produce una ilusión de bonanza empresarial que no tiene base y explica que los empresarios empiecen a consumir ganancias que no se han producido, lo cual aumenta aún más la presión de la demanda de bienes de consumo. 
Se resalta el efecto de esa subida más rápida del precio de los bienes de consumo ( en relación a la subida del precio de los factores de producción ) al dedicarse más factores de producción a los procesos más alejados del consumo que (sólo después de un largo periodo de tiempo comienzan a producir sus resultados) reduce el ritmo de llegada de bienes de consumo al mercado. Así, ese alargamiento de los procesos productivos se financia con créditos creados sin respaldo de un aumento previo del ahorro de la banca. Y al no existir un aumento previo del ahorro $\mathrm{y}$, por tanto, no quedar liberados bienes de consumo para hacer posible el mantenimiento de la sociedad (mientras se culmina ese alargamiento de las etapas productivas y el traslado de los factores de producción desde las etapas más cercanas al consumo hacia las etapas más alejadas del consumo) subirá el precio de los bienes de consumo.

\section{3o Aumento de las ganancias de las empresas de las etapas más cercanas}

La subida del precio de los bienes de consumo a un ritmo más rápido que la subida del precio de los factores de producción; aumenta las ganancias de las empresas de las etapas más cercanas al consumo ( con respecto a las ganancias de las empresas de las etapas más alejadas del consumo ) porque sus costos de producción (aun presionando al alza) no aumentan a un ritmo más rápido.

En las etapas más alejadas del consumo; el precio de los bienes intermedios (producidos en cada etapa) no aumenta significativamente, mientras que el precio de los factores de producción ( empleados en cada etapa ) aumenta significativamente (por la mayor demanda de esos factores de producción que tiene su origen directo en la política monetaria expansiva); lo cual reduce las ganancias de las empresas de las etapas más alejadas del consumo, como resultado de un aumento de los costos más rápido que el aumento de los ingresos. 
El efecto combinado de ambos efectos es que empieza a ponerse de manifiesto (a lo largo de toda la estructura productiva) que las ganancias de las etapas más cercanas al consumo son más altas que las ganancias de las etapas más alejadas del consumo. Esto inicia un movimiento espontáneo de los empresarios para reconsiderar sus inversiones, e incluso dudar de sus inversiones y a replantearse la necesidad de revertir la inversión inicial de sus recursos, retirándolos de los proyectos más intensivos en capital que no hace mucho comenzaron; para llevarlos de nuevo hacia las etapas más cercanas al consumo. En un entorno de aumento de la productividad no se observará una subida de los precios (unitarios) de los bienes de consumo, pero si un gran aumento en el importe (monetario) de las ventas y ganancias de las empresas más cercanas al consumo.

40 El Efecto Ricardo es el efecto inmediato del aumento del ahorro sobre los salarios reales; donde el aumento de los salarios reales hace rentable para los empresarios de todas las etapas del proceso productivo sustituir mano de obra por bienes de capital, en opinión de Ravier (2015). La subida más rápida del precio de los bienes de consumo respecto al aumento de los ingresos nominales de los factores de producción; disminuye esos ingresos reales de los factores de producción; con lo que los empresarios tienen un incentivo para sustituir (por el Efecto Ricardo "que se basa en una comparación relativa de costos" maquinaria y equipo capital por trabajadores. Así, disminuye la demanda de bienes de capital y de bienes intermedios de las etapas más alejadas del consumo, lo cual agrava aún más el problema de la disminución de las ganancias (e incluso pérdidas) que ya empezó a sentirse en esas etapas más alejadas del consumo.

Además, el Efecto Ricardo es una manifestación de que los nuevos proyectos de inversión maduran en un futuro lejano, teniendo en cuenta las circunstancias reales del mercado, 
por lo que no podrán culminarse por falta de rentabilidad. El hecho de que por vía sindical y coactiva se logre un aumento de los salarios a un ritmo parecido al del aumento del precio de los bienes de consumo, en nada perjudica este argumento, pues seguirían ejerciendo su efecto las 5 razones y el Efecto Ricardo, puesto que siempre, al menos en términos relativos, el precio de los factores de producción empleados en las etapas más cercanas al consumo será más reducido que el de los recursos empleados en las etapas más alejadas, con lo cual el Efecto Ricardo, que se basa en una comparación relativa de costos, seguiría operando (las etapas más cercanas al consumo seguirían contratando en términos relativos más mano de obra que equipo capital). Los incrementos coactivos de rentas de los factores de producción tan sólo lograrían, en última instancia, que se produjera un importante crecimiento en el volumen de desempleo involuntario de los mismos, especialmente agravado en las etapas más alejadas del consumo. Además, la prima de riesgo empieza a crecer conforme surgen dudas sobre la viabilidad de los distintos proyectos de inversión.

\section{5o Aumento de la tasa de interés a un nivel más elevado del que tenía antes de comenzar la Política Monetaria Expansiva.}

La subida de la tasa de interés en el mercado de crédito ocurre cuando se detiene la política monetaria expansiva: la tasa de interés volverá a subir a los niveles altos; que el nivel que tenía antes de comenzar tal política monetaria expansiva.

Sí la tasa de interés antes de comenzar tal política monetaria expansiva era alta (por ejemplo 5\%) cuando comienza tal política monetaria expansiva esa tasa de interés se reduce (por ejemplo a 2\%) y se facilita los requisitos para la concesión de créditos (como las garantías contractuales); cuando se detenga esa política monetaria expansiva; la tasa de interés volverá a subir a su nivel de $5 \%$; e incluso subirá por encima de ese 5\% por el efecto combinado de 2 causas: 
a) La política monetaria expansiva aumenta el precio de los bienes de consumo (por ejemplo en 2\%). Por ello, si los prestamistas quieren cobrar esa misma tasa de interés previa de por ejemplo $3 \%$, deberán añadir ese componente por la inflación de $2 \%$ a esa tasa de interés previa de $3 \%$ al comienzo de esa política monetaria expansiva.

b) Los empresarios que han decidido alargar los procesos productivos (a pesar de que la tasa de interés ha subido) y en la medida en que ya han comprometido importantes recursos en nuevas inversiones; estarán dispuestos a pagar esas tasas de interés más altas, con tal de que se les proporcionen los fondos necesarios para culminar esas inversiones que por error han emprendido: el proceso de inversión en bienes de capital genera una demanda autónoma de posteriores bienes de capital; (bienes de capital complementarios a los bienes de capital ya producidos). Este fenómeno durará mientras se mantengan las expectativas de que esos procesos productivos podrán culminarse, por lo que los empresarios demandaran nuevos créditos, no importando cuál sea el costo de esos nuevos créditos, antes que verse forzados a reconocer su fracaso y a abandonar unos proyectos de inversión en los que han comprometido importantes recursos. Como consecuencia de ello, el aumento de la tasa de interés en el mercado crediticio (al final del auge) se debe a fenómenos monetarios y reales que afectan a la demanda de nuevos créditos: los empresarios, empeñados en completar las nuevas etapas más intensivas en capital que han emprendido y que comienzan a ver peligrar; recurren a los bancos demandando dosis adicionales de créditos, y ofreciendo una tasa de interés cada vez más elevada, por esos créditos de manera que comienzan una competencia por obtener financiación adicional.

\section{6- Las pérdidas de las empresas de las etapas más alejadas del consumo: la llegada de la crisis}

El resultado combinado de esos 5 efectos determina que, tarde o temprano, aparezcan las pérdidas de las empresas de las etapas más alejadas del consumo. Estas pérdidas (comparadas con las ganancias 
que se obtienen en las etapas más cercanas al consumo) ponen: por finalizados los errores empresariales; y la forzosa necesidad de reconvertirlos, procediendo a la paralización y posterior liquidación de las inversiones erróneamente emprendidos, retirando factores de producción de las etapas más alejadas del consumo para trasladarlos de nuevo a las etapas más cercanas al consumo.

Los empresarios se dan cuenta que es necesario reajustar masivamente la estructura productiva. Es decir, una reconversión o reestructuración retirándose de las inversiones que emprendieron en las etapas de las industrias de bienes de capital y que no pudieron culminar con éxito, trasladando lo que queda de sus factores de producción hacia las industrias más cercanas al consumo. Hay que liquidar las inversiones que ahora no son rentables y trasladar masivamente los factores de producción y la mano de obra hacia las etapas más cercanas al consumo.

Así, ha llegado la crisis y la recesión, por falta de recursos ahorrados para completar unas inversiones que (según se ha puesto de manifiesto) eran excesivamente ambiciosas. La crisis se manifiesta en un exceso de inversión en las etapas más alejadas del consumo (en las industrias de bienes de capital: altos hornos, construcción, comunicaciones, nuevas tecnologías) y en las etapas que ensancharon su estructura de bienes de capital; y una paralela escasez relativa de inversión en las industrias más cercanas al consumo.

El resultado combinado de ambos errores: una generalizada mala inversión de los factores de producción (una inversión con un estilo, calidad, cantidad y distribución geográfica y empresarial propios de una situación en que el ahorro era mucho mayor que el ahorro que realmente se ha producido). Se ha invertido en forma y cantidad indebida en los lugares erróneos de la estructura productiva, porque los empresarios pensaban (engañados por la expansión del crédito) que el ahorro de la sociedad iba a ser mucho mayor.

Los empresarios se han dedicado a alargar las etapas de bienes de capital más alejadas del consumo, con la esperanza de que (una vez que los nuevos procesos de inversión se hubieran culminado 
temporalmente, se incrementaría de manera muy significativa la abundancia final de bienes de consumo). Sin embargo, ese proceso de alargamiento de la estructura productiva exige un periodo de tiempo largo; hasta que la sociedad pueda llegar a beneficiarse del aumento en la producción de bienes de consumo. Y los agentes económicos no están dispuestos a esperar ese periodo de tiempo largo; y al actuar manifiestan sus preferencias demandando los bienes de consumo ahora, es decir, mucho más pronto de lo que se exigiría para culminar el alargamiento emprendido en la estructura productiva.

\section{Evidencia Empírica: Caso Peruano Enero 2004 - Octubre 2017}

Para la prueba empírica se consideró la variación porcentual mensual del Producto Bruto Interno Peruano período Enero 2004 - Octubre 2017, la variación porcentual mensual de la Liquidez Peruana 2004 - Octubre 2017 y el nivel mensual porcentual de la Tasa de Interés de Referencia Peruana Enero 2004 - Octubre 2017 según las estadísticas económicas publicadas en la página web del Banco Central de Reserva del Perú. Se estima este Modelo utilizando la técnica econométrica Método de Mínimos Cuadrados Ordinarios que evalúa los efectos del nivel de la tasa de interés de referencia y de la liquidez en las fases de auge y recesión del Producto Bruto Interno PBI; y se prueba que "los auges y caídas del PBI de duración variable son provocadas por la política monetaria"; toda vez que en conjunto la liquidez y la tasa de interés de referencia influyó en el PBI. Así, para el mencionado período; las estimaciones realizadas evidencian que la evolución de la tasa de interés de política monetaria y la liquidez influyó en el ciclo económico peruano. Por lo que el Aporte al Estudio de la Política Monetaria y los Ciclos Económicos es que la Política Monetaria mediante el Control directo de la liquidez han generado Ciclos Económicos durante tal período; y que se evitará los ciclos económicos mediante modificaciones de las tasas de interés de referencia que coincidan con la variación del PBI. 
Dependent Variable: PBI

Method: Least Squares

Date: 02/01/18 Time: 10:20

Sample (adjusted): 2004M03 2017M10

Included observations: 164 after adjustments

Convergence achieved after 16 iterations

\begin{tabular}{lclcc}
\hline \hline \multicolumn{1}{c}{ Variable } & Coefficient & Std. Error & t-Statistic & Prob. \\
\hline \hline C & 3.426709 & 2.422585 & 1.414485 & 0.1592 \\
LIQ & 0.235716 & 0.099277 & 2.374323 & 0.0188 \\
TIR & 0.457880 & 0.578509 & 0.791482 & 0.4298 \\
DUM1*TIR & -0.008143 & 0.056494 & -0.144133 & 0.8856 \\
AR(1) & 0.377502 & 0.072850 & 5.181879 & 0.0000 \\
AR(2) & 0.449499 & 0.077267 & 5.817512 & 0.0000 \\
\hline \hline R-squared & 0.618078 & Mean dependent var & 5.524676 \\
Adjusted R-squared & 0.605992 & S.D. dependent var & 3.146038 \\
S.E. of regression & 1.974771 & Akaike info criterion & 4.234682 \\
Sum squared resid & 616.1560 & Schwarz criterion & 4.348091 \\
Log likelihood & -341.2439 & Hannan-Quinn criter & 4.280722 \\
F-statistic & 51.13934 & Durbin-Watson stat & 2.090575 \\
Prob(F-statistic) & 0.000000 & & \\
\hline \hline Inverted AR Roots & .89 & -.51 & \\
\hline \hline
\end{tabular}

Graficando los Residuos y la evolución del PBI, la Liquidez y la Tasa de Interés de Referencia

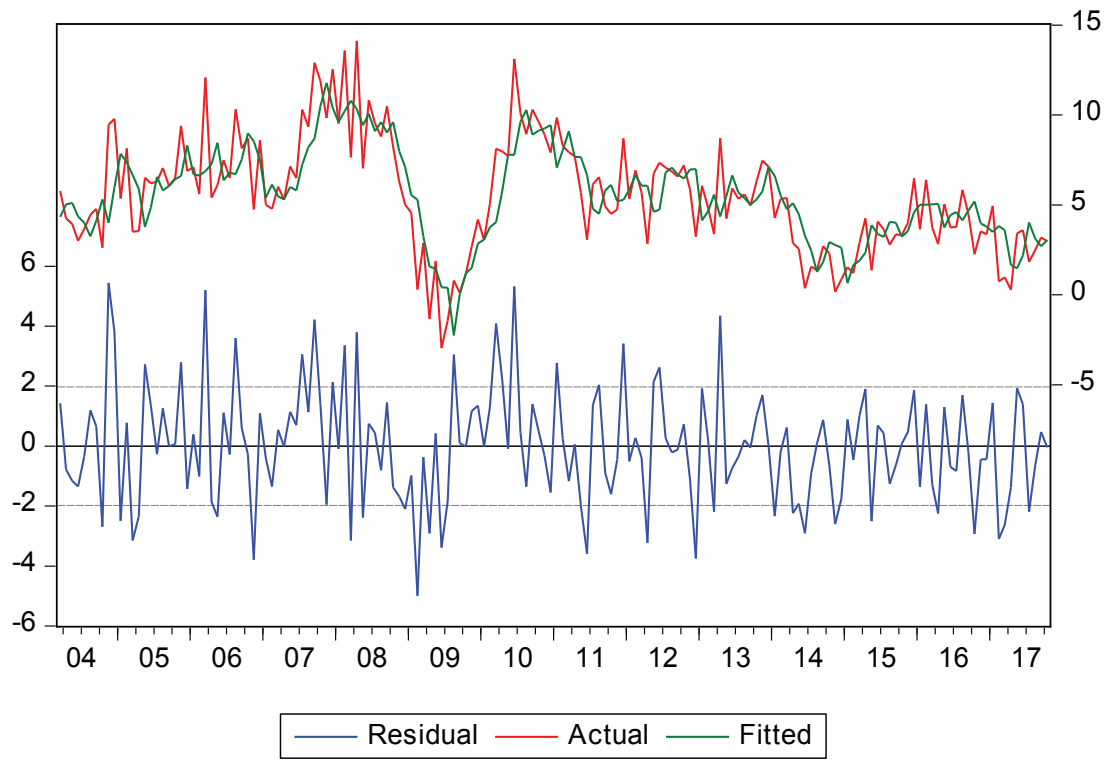


Pensamiento Crítico Vol. 22. $\mathrm{N}^{\circ} 2$
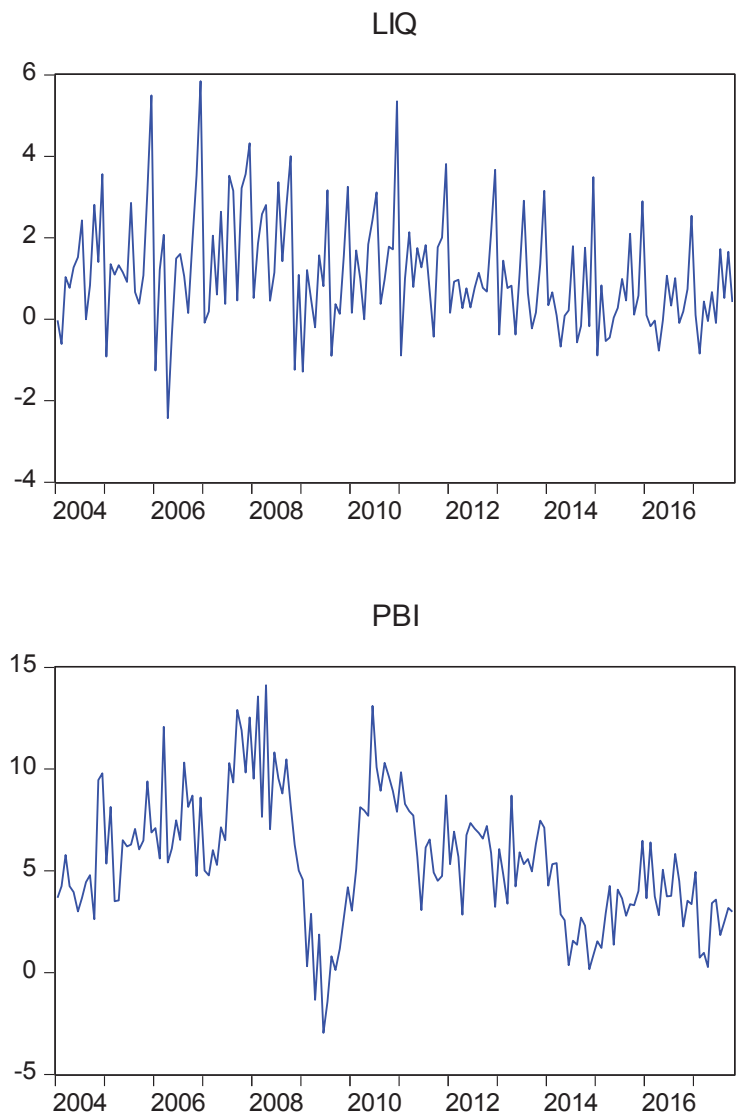

TIR

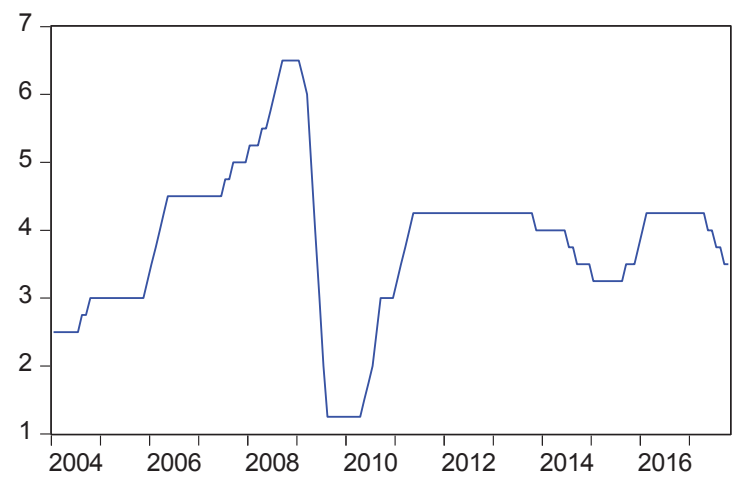




\section{Conclusiones}

La Política Monetaria Expansiva sin respaldo de aumento previo del ahorro motiva que los empresarios actúen como si el ahorro de la sociedad hubiera aumentado mucho, en el volumen en que la banca haya creado nuevos créditos. Los procesos analizados; hacen que (de manera espontánea e ineludible) se ponga de manifiesto el error cometido, ya que el ciclo económico es un caso particular de los errores de cálculo económico a que da lugar el intervencionismo del Estado en la economía (en este caso sobre el campo monetario y crediticio).

Este error tiene su origen en que los agentes económicos durante mucho tiempo creyeron que el ahorro disponible era mucho mayor que el ahorro que en realidad había. El error cometido es semejante al error en que incurría un constructor que, equivocándose en cuanto a la cantidad de los materiales de construcción a su disposición, los agotase completamente en la construcción de los cimientos, viéndose forzado a dejar inacabado el edificio. Por tanto, se trata de una crisis de exceso de consumo (o de escasez de ahorro) que ha puesto de manifiesto no ser suficiente el ahorro para completar las inversiones más intensivas en capital que se comenzaron por error. Como resultado de todo ello, numerosas fábricas de las etapas más alejadas del consumo se cierran, se paralizan gran cantidad de proyectos de inversión emprendidos por error, y muchos trabajadores son despedidos. Además, a lo largo de toda la sociedad se generaliza el pesimismo, y la idea de que se ha entrado en una inexplicable crisis, justo poco tiempo después de que llegara a creerse que el auge y el optimismo (lejos de haber alcanzado su cumbre) iban a tener una duración ilimitada; desmoraliza incluso a los que disfrutan de más ánimo.

Así, se explica los fundamentos microeconómicos del movimiento contrario al movimiento espontáneo; que se produce en el mercado cuando se verifica una política monetaria expansiva y que genera ciclos sucesivos de auge y recesión que regularmente experimentan las economías. No existe posibilidad teórica para que ese control reduzca los sacrificios que exige todo proceso de crecimiento económico e impulse y acelere tal crecimiento económico (sin que los ciudadanos decidan ahorrar). 


\section{Referencias Bibliográficas}

Lucas, R. (1987). Teoría de los ciclos económicos. Madrid: Alianza editorial.

Mundell, R. (1971). Teoría monetaria. Madrid: Ediciones Amorrurtu Editores. Pag. 323-430.

Neira, M.; Bagus, P. y Rallo J. (2010). La crísis subprime a la luz de la teoría austriaca del ciclo económico: expansión crediticia, errores de decisión y riesgo mopral. Revista de Economía Mundial Volumen N² 28. Pag. 145-171.

Ravier O. (2015). Repensando la macroeconomía del capital. Revista de Instituciones. Ideas y Mercado. p. 5 - 37. Madrid.

Von Hayek, F. (1978). Desnacionalización del dinero. Madrid: Editorial Continental. Pag. 143-187.

Von Mises, L. (1980). Acción humana. Madrid: Fundación Ignacio Villalonga. 
Pablo Hermenegildo Rivas Santos

228 